\title{
MEMORIAL 10 ANOS DO PROGRAMA DE MESTRADO EM DESENVOLVIMENTO REGIONAL DA UNIVERSIDADE DO CONTESTADO
}

\author{
Argos Gumbowsky \\ Maria Luiza Milani ${ }^{2}$ \\ Sandro Luiz Bazzanella ${ }^{3}$
}

\begin{abstract}
RESUMO
O texto aborda aspectos relacionados à trajetória da legitimação do Stricto Sensu na Universidade do Contestado (UnC), bem como do Programa de Mestrado em Desenvolvimento Regional (PMDR) na UnC, desde sua autorização em questões de processo, avanços e desafios. A pesquisa de características quali-quantitativa e descritiva revela que mesmo com os enfrentamentos, o PMDR demonstra relevante contribuição ao desenvolvimento, não apenas na abrangência territorial do Planalto Norte Catarinense (PNC). Analisando a sua trajetória de 10 anos, o PMDR contribui com a formação de pesquisadores e intelectuais. Evidencia fundamentos éticos $\mathrm{e}$ políticos da multiprofissionalidade $\mathrm{e}$ interdisciplinaridade, pelos quais sujeitos e atores devem mover-se no rumo do bem estar da sociedade. Internamente, o PMDR como processo vivo, avança nos seus compromissos e fundamentos, quando cerca as dimensões do desenvolvimento por duas linhas de pesquisa: a) Políticas Públicas e Desenvolvimento Regional; b) Gestão, Território e Desenvolvimento. As dissertações defendidas mesmo abordando a abrangência local e microrregional, promovem análises de temáticas vinculadas às necessidades humanas e socioeconômicas, com destaque para a saúde, educação, agricultura e pecuária, meio ambiente e indústria e comércio. A produção científica do PMDR sustenta também os meios de comunicação e as intervenções sociais dos múltiplos atores, ao mesmo tempo em que se constitui como fonte fidedigna dos anseios, demandas e perspectiva de desenvolvimento não apenas do Planalto Norte Catarinense, mas de qualquer território ousado que deseje modificar e superar os impasses do bem estar da sociedade.
\end{abstract}

Palavras chave: Stricto Sensu. Desenvolvimento Regional. Universidade do Contestado.

\section{A TRAJETÓRIA DO PMDR}

O Programa de Mestrado em Desenvolvimento Regional (PMDR), em 2016 completa 10 anos de existência. Sua concepção é mais antiga. Parte de um compromisso da Universidade do Contestado, com o desenvolvimento das regiões onde se situa. Para a

\footnotetext{
${ }^{1}$ Doutor em Educação, docente do Programa de Mestrado em Desenvolvimento Regional, Coordenador do PMDR desde janeiro de 2016. Santa Catarina Brasil. E-mail: $\underline{\operatorname{argos} @ \text { unc.br }}$

${ }^{2}$ Doutora em Serviço Social, docente do Programa de Mestrado em Desenvolvimento Regional, Coordenadora do PMDR entre 2006 e 2013. Santa Catarina Brasil. E-mail: marialuiza@unc.br

${ }^{3}$ Doutor em Ciências Humanas, docente do Programa de Mestrado em Desenvolvimento Regional, Coordenador do PMDR entre 2014 e 2015. Santa Catarina Brasil. E-mail: sandroluizbazzanella@gmail.com
} 
concepção do PMDR, movimentos e decisões foram tomadas. Docentes foram qualificados, projetos foram desenvolvidos. Interações, parcerias, publicações e um intenso debate sobre as definições do seu eixo condutor: área de concentração e linhas de pesquisas, objetivos e cumprimento dos propósitos institucionais.

Passado seu planejamento e autorização pela Coordenação de Aperfeiçoamento de Pessoal de Nível Superior (CAPES), o PMDR passa a ser ofertado à comunidade localregional-nacional em agosto de 2006. Com empenho e condições objetivas delineadas, o Mestrado da UnC, como é referenciado, caracteriza-se por composição multiprofissional e pela execução das disciplinas, estudos e pesquisas de caráter interdisciplinar. Esta configuração é sustentada por duas linhas de pesquisas: Políticas Públicas e Desenvolvimento Regional e Gestão, Território e Desenvolvimento.

O texto a seguir é congregado por vários elementos, os quais devem oportunizar uma visão de dentro e de fora da realidade social que contorna o PMDR. Como afirmado, este mestrado é a concretização do compromisso institucional da UnC com a formação nas diversas etapas acadêmicas, por isso o Stricto sensu se tornou projeto e se transformou em realidade a partir dos anos 2000 .

Em seguida, este texto apresenta dados e índices que evidenciam a intensa atividade acadêmica de seus docentes e discentes. Não são apenas números que dão sentido aos alcances do PMDR, é sim o envolvimento com os distintos espaços, estratégias, recursos, grupos e sociedade local-regional-nacional e internacional. O PMDR se torna um ator relevante. Por meio de seus docentes e discentes, a UnC se projeta nacional e internacionalmente.

Na continuidade, não falamos de "flores". Em toda jornada, o movimento dialético do ir e vir integra a passagem da quantidade para a qualidade, da luta dos contrários, da negação da negação. A cada dissertação o PMDR agiu e reagiu. Isso se evidencia no presente texto para que a comunidade local-regional-nacional-internacional constate que mesmo os impasses não representaram desânimo, mas a condição de possibilidade de reconhecimento e superação dos desafios que constantemente se apresentam. Assim se apresentaram os 10 anos, aprendizados-reaprendizados-revisão dos aprendizados.

Para finalizar os escritos e na perspectiva dos próximos 10 anos, os cenários se mostram férteis de desafios, não emergindo apenas da contemplação, mas se evidenciando pela ciência e pela clareza de cada integrante desse ator social. Cada integrante, a seu modo, desvela uma faceta do contraditório e complexo processo do desenvolvimento.

O que nos resta? Muitas questões, as quais são indicadas ao final dessa valiosa rememoração. Comemorar uma existência é analisar sua gênese, sua trajetória, avaliar os percalços, indicar os desafios.

\section{SEUS ANTECEDENTES}

O PMDR representa um saldo qualitativo na e da UnC. Sua gênese se reporta ao campus universitário de Canoinhas, o qual foi instituído a partir da lei municipal $n^{\circ} .954$, de 07 de dezembro de 1970, do município de Canoinhas/SC, com a denominação de Fundação

DRd - Desenvolvimento Regional em debate (ISSNe 2237-9029) 
Universitária do Planalto Norte Catarinense (FUNPLOC). Em 28 de março de 1990, juntamente com instituições de ensino superior estabelecidas nos municípios de Caçador, Concórdia, Mafra e Curitibanos passou a integrar a Federação das Fundações Educacionais do Contestado (FENIC) que em 29 de abril de 1994 foi convertida na Fundação Universidade do Contestado, confirmada em 21 de outubro de 1997pelo parecer n $42 / 97$, do Conselho Estadual de Educação (CEE).

O reconhecimento da UnC como Universidade foi oficializado em 03 de dezembro de 1997, pelo parecer n²46/97, do mesmo CEE catarinense.

Em 03 de março de 2009, o Conselho de Administração Superior (CAS), órgão integrante da mantenedora da Fundação Universidade do Contestado deliberou o processo de unificação de 05 unidades da UnC (Canoinhas, Mafra, Curitibanos, Concórdia e Porto União) para um CNPJ Único, com o objetivo de atender à legislação e aos pronunciamentos do Ministério Público de Santa Catarina, responsável por velar pelas Fundações.

A Universidade do Contestado, visando à integração dos níveis de ensino de graduação, pesquisa e extensão, prioriza os encaminhamentos e discussões sobre os problemas regionais, buscando a apropriação e a transmissão de conhecimentos, de tecnologias e metodologias para a geração do desenvolvimento socioeconômico e político da região.

\section{O PMDR APROVADO}

Materializando um desejo da UnC, o Programa de Mestrado em Desenvolvimento Regional inicia suas atividades em 2006 quando é ofertada a primeira turma.

O credenciamento e reconhecimento necessários à sua oficialidade é resultante das reuniões do Conselho Técnico Científico da CAPES, ocorridas em 31 de janeiro, $1^{\mathrm{o}}$ e 2 de fevereiro de 2006, quando foram avaliados e atribuídos conceitos aos Programas de PósGraduação Stricto sensu que pleitearam ingresso no sistema de avaliação, dentre eles, o Programa de Mestrado em Desenvolvimento Regional da UnC. Na data de 08 de junho de 2006, o Conselho Nacional de Educação, através do Parecer CNE/CES n ${ }^{\circ}$ 165/2006, deliberou favoravelmente pelo reconhecimento do PMDR, com prazo de validade determinado pela sistemática avaliativa da CAPES, aplicável aos Programas de Mestrado e Doutorado, aprovando-o com conceito " 3 " e atribuindo validade nacional aos títulos de Mestre nele obtidos.

No âmbito estadual, o Conselho Estadual de Educação pelo Parecer CEDS no 42, de 22 de maio de 2006, aprovou a comunicação da implantação do Programa de Mestrado em Desenvolvimento Regional, haja vista o cumprimento do rito prescrito na Resolução $\mathrm{n}^{\mathrm{o}}$ 001/2001/CEE, que dispunha sobre a oferta de Programas de Pós-Graduação Stricto Sensu.

Neste ínterim, enquanto tramitava o processo que pleiteava o ingresso do PMDR no sistema de avaliação da CAPES, em 22 de março de 2006, a Resolução UnC-CONSEPE n ${ }^{\circ}$ 018/2006, aprovou a adequação do Programa de Mestrado em Desenvolvimento Regional às sugestões do Parecer da Comissão de Área de Avaliação CAPES - Planejamento Urbano Regional/Demografia e na área de concentração Desenvolvimento Regional. 


\section{A TRAJETÓRIA DE 2006 A 2016}

No decorrer de 10 (anos) anos de atividades, o PMDR vem continuamente promovendo o ensino e a pesquisa na área do desenvolvimento regional, orientado pelos pressupostos multi e interdisciplinares, tendo a região do Contestado como contexto referencial de análise inicial.

Com o intuito de caracterizar a multiprofissionalidade, a composição do seu corpo docente, tem formação nas Ciências Humanas, Sociais Aplicadas, Agrárias e Saúde, Biológicas. A titulação dos docentes, pela diversificada formação, evidencia atributos que historicamente distinguem o PMDR. Ou seja, a capacidade de operar, integrando diferentes áreas do conhecimento, com o objetivo de valorizar a interdisciplinaridade.

As áreas com maior número de representantes no período do estudo foram: educação com 16,7\%; geografia e ciências ambientais e ciências agrárias I, com 11,1\% cada (Gráfico 1). A diversidade de formação dos docentes demonstra a capacidade de produção de trabalhos multidisciplinares.

Gráfico 1 - Programa de Mestrado em Desenvolvimento regional da UnC por áreas de formação da CAPES

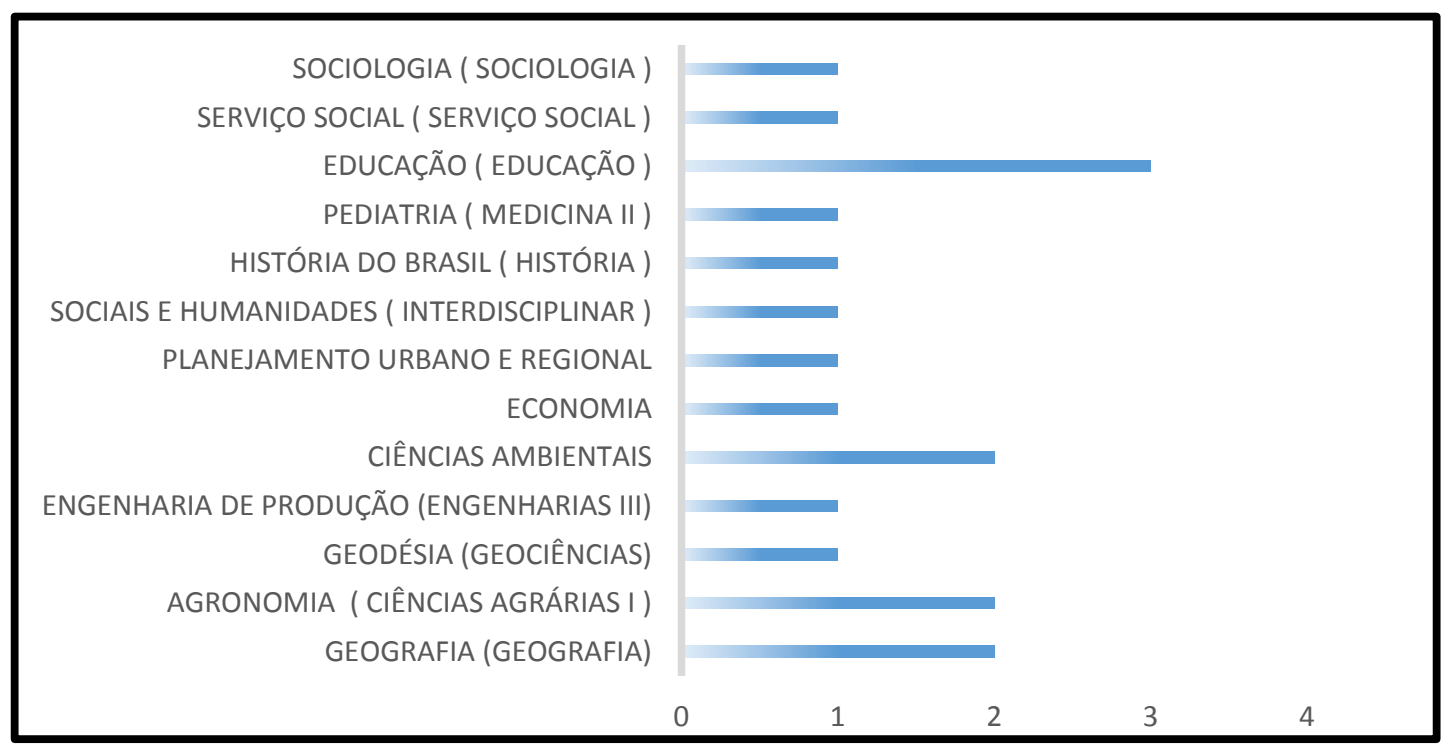

Fonte: Secretaria PMDR (2016)

Visando fortalecer continuamente seus atributos, o Programa de Mestrado em Desenvolvimento Regional mantém, hodiernamente, quadro de docentes com titulação multidisciplinar.

Sob esse viés, de 2006 até o ano de 2010, o PMDR manteve a linha de pesquisa designada "Políticas públicas e Desenvolvimento Regional". Na reestruturação promovida do Projeto Pedagógico original do Programa, durante o ano de 2010, foi criada uma segunda linha: "Gestão, Território e Desenvolvimento". 
Linha 1: Políticas Públicas e Desenvolvimento Regional: As pesquisas priorizam processos envolvendo o desenvolvimento socioeconômico, político, cultural e educacional, de abrangência regional, produzidos ou não por políticas públicas que, com seus diferentes arranjos, conectam os espaços públicos e privados dos ambientes urbanos e rurais, tendo como contexto referencial de análise inicial, a região do Contestado.

Linha 2: Gestão, Território e Desenvolvimento: Entende-se gestão como ato de gerência e administração, contemplando as dimensões pública, privada e social. Portanto, a gestão articula-se em torno de ações públicas e privadas, que ocorrem nos diferentes territórios, com vistas ao desenvolvimento.

Sob as linhas da área básica e área de concentração, o PMDR da UnC, define seus objetivos:

-Fortalecer o papel da Universidade como agente disseminador do conhecimento científico para fomento do desenvolvimento regional;

-Construir prática de ensino e pesquisa multi e interdisciplinar para que se estabeleça influência recíproca e solidária entre teoria e prática no Planejamento Urbano e Demografia, bem como uma visão global da complexidade apresentada pelo tema: desenvolvimento regional;

-Formar profissionais com capacidade técnica, científica e ética, para a atuação em instituições públicas ou privadas;

- Avaliar a capacidade das políticas educacionais como instrumento para o desenvolvimento regional;

- Analisar a influência e a eficácia das políticas públicas nas relações de complementaridade entre as esferas pública e privada;

-Revitalizar a identidade cultural e política do Contestado;

-Interpretar os modelos de gestão pública e social, nas escalas das políticas do desenvolvimento: local, regional, nacional e internacional;

- Analisar as iniciativas de desenvolvimento agrossilvopastoril para a região do Contestado;

-Estimular pesquisas para a integração do planejamento regional ao municipal, analisando as condições da organização dos espaços urbano e rural para a melhoria de qualidade de vida;

-Instrumentalizar a elaboração de projetos de intervenção que visem à integração da comunidade regional.

-No ano do seu décimo aniversário, ingressou a Turma XI e já foi concluída a formação 110 Mestres em Desenvolvimento Regional. 
Em termos de conhecimentos que destaquem o Planalto Norte Catarinense como recorte territorial de análise, desde o início de suas atividades em 2006 até fevereiro de 2015, foram defendidas 88 dissertações, havendo equidade entre as linhas de pesquisa (44 em cada). O equilíbrio demonstra que a decisão de criar a linha de pesquisa 2: Gestão, território e desenvolvimento em 2010 foi adequada na medida em que contempla $50 \%$ das pesquisas conduzidas e defendidas no Programa.

Quanto a abrangência dos temas tratados nas dissertações, o Gráfico 4 mostra que mesmo tendo predominância na escala local, o somatório das demais (estadual, regional nacional e macrorregional) evidencia que o lastro da territorialização não desvia o foco das reflexões sobre a abrangência regional.

Gráfico 2 - Abrangência territorial tratado pelas dissertações

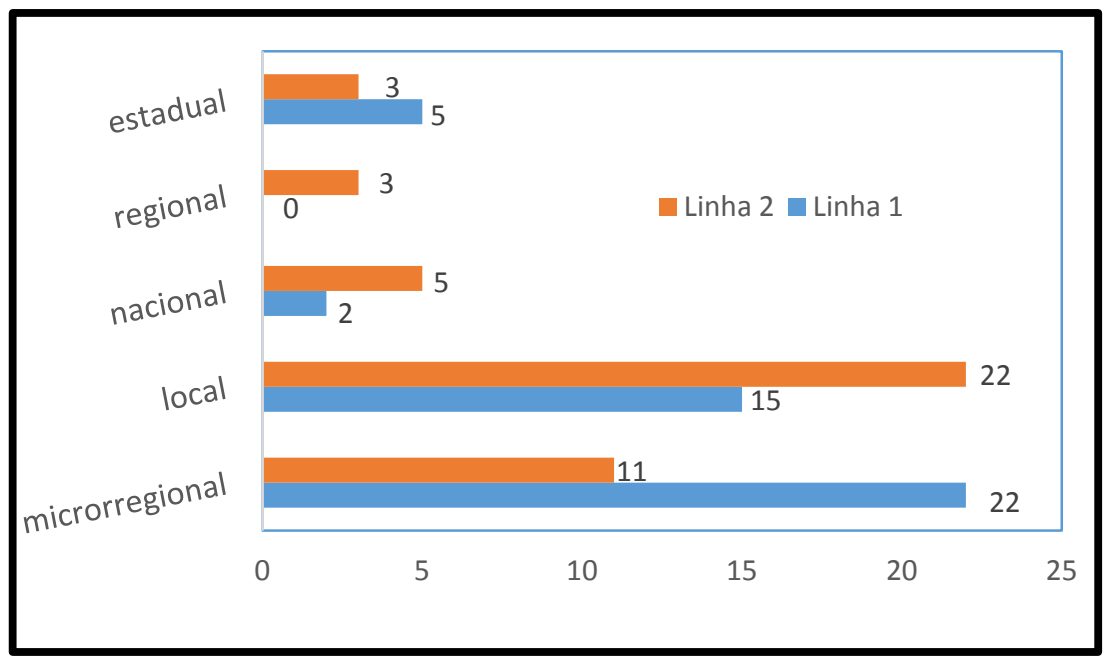

Fonte: Secretaria PMDR (2016)

Com relação aos temas abordados nas dissertações defendidas no PMDR da UnC, esses são agrupados em cinco áreas das políticas públicas (saúde, educação, agricultura e pecuária, meio ambiente e indústria ou comércio) que transitam entre as duas linhas de pesquisa. 
Gráfico 3 - Classificação em categorias das temáticas abordadas nas dissertações do PMDR

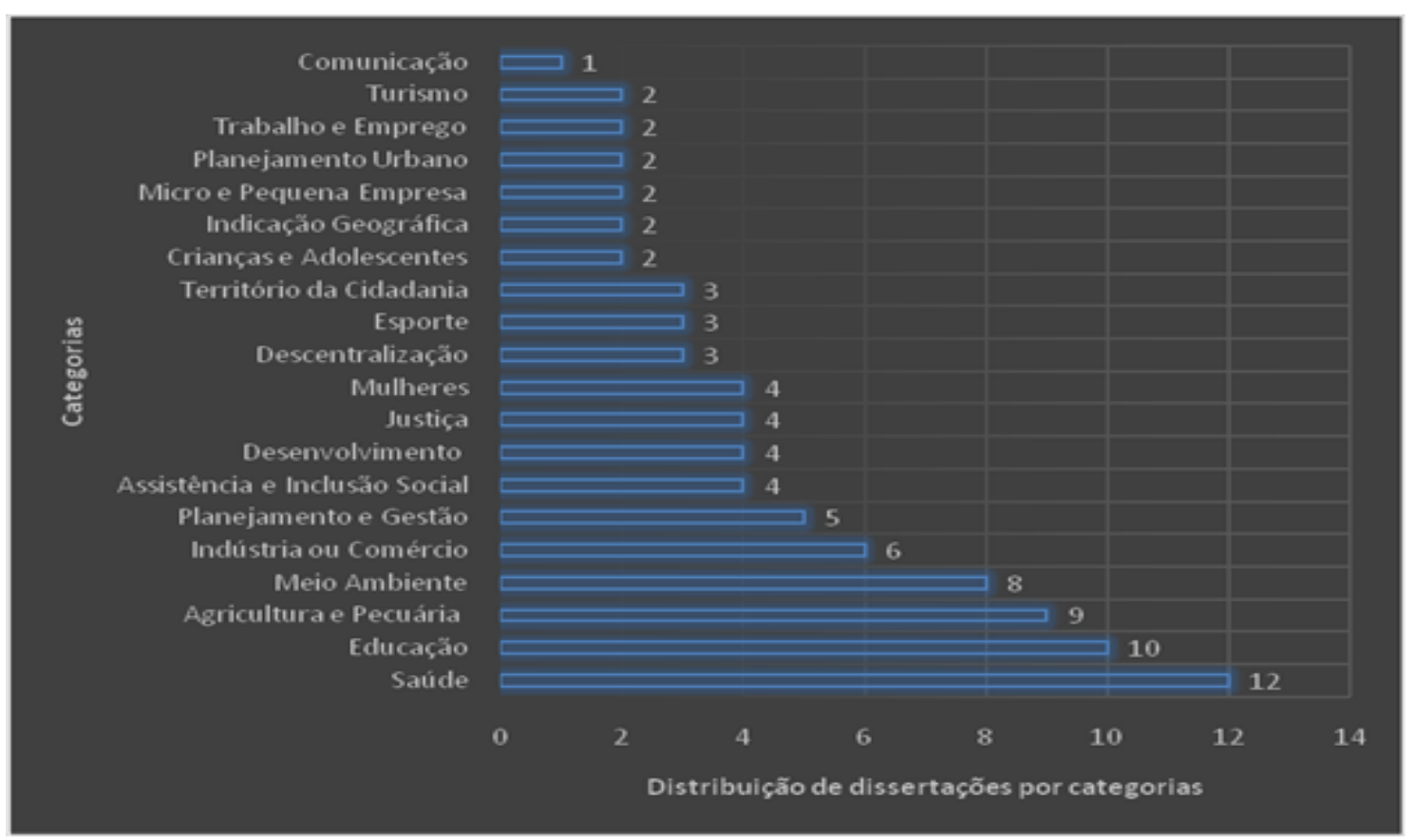

Fonte: Secretaria PMDR (2016)

Das cinco áreas das políticas públicas, a identificação de 20 categorias distintas, indica a robustez do atributo de interdisciplinaridade no âmbito do PMDR. Nesse contexto, torna-se conveniente demonstrar os objetos de pesquisas das dissertações classificados em temáticas principais e temáticas secundárias, anteriormente já distribuídas em categorias. A Tabela 5 cumpre este propósito, evidenciando pormenorizadamente as temáticas principais e temáticas secundárias abordadas:

Tabela 1 - Categorias, temáticas principais e temáticas secundárias das dissertações defendidas no PMDR

(Continua...)

\begin{tabular}{|c|c|c|c|c|c|}
\hline CATEGORIA & $\begin{array}{l}\text { TEMÁTICA } \\
\text { PRINCIPAL }\end{array}$ & TEMÁTICA SECUNDÁRIA & LINHA & $\begin{array}{c}\text { QUANTIDA } \\
\text { DE }\end{array}$ & $(\%)$ \\
\hline \multirow{12}{*}{ Saúde } & \multirow{12}{*}{ Saúde } & Mortalidade Infantil & 01 & \multirow{12}{*}{12} & \multirow{12}{*}{13,64} \\
\hline & & Bucal & 01 & & \\
\hline & & Diabético & 01 & & \\
\hline & & Família & 01 & & \\
\hline & & Idoso & 01 & & \\
\hline & & Justiça & 01 & & \\
\hline & & Parto & 01 & & \\
\hline & & União da Vitória & 01 & & \\
\hline & & Visual & 01 & & \\
\hline & & $\begin{array}{l}\text { SUS e Agentes Comunitários } \\
\text { de Saúde }\end{array}$ & 01 & & \\
\hline & & Financiamento Público & 02 & & \\
\hline & & Bucal & 02 & & \\
\hline \multirow{4}{*}{ Educação } & \multirow{4}{*}{ Educação } & Crianças ou Adolescentes & 01 & \multirow{4}{*}{10} & \multirow{4}{*}{11,36} \\
\hline & & Crianças ou Adolescentes & 01 & & \\
\hline & & Gestão Pública & 01 & & \\
\hline & & Qualidade do Ensino & 01 & & \\
\hline
\end{tabular}

DRd - Desenvolvimento Regional em debate (ISSNe 2237-9029)

v. 6, n. 2, ed. esp., p. 5-25, jul. 2016. 
(Continua...)

\begin{tabular}{|c|c|c|c|c|c|}
\hline & & Patrimônio Cultural & 01 & & \\
\hline & & Agronegócio & 01 & & \\
\hline & & Desenvolvimento & 01 & & \\
\hline & Extensão Universitária & Instituição de Ensino Superior & 01 & & \\
\hline & $\begin{array}{l}\text { Instituição de Ensino } \\
\text { Superior }\end{array}$ & Desenvolvimento & 01 & & \\
\hline & Legislação & Instituição de Ensino Superior & 01 & & \\
\hline \multirow{9}{*}{$\begin{array}{l}\text { Agricultura e } \\
\text { Pecuária }\end{array}$} & \multirow{3}{*}{ Agricultura Familiar } & Saúde & 01 & \multirow{9}{*}{9} & \multirow{9}{*}{10,23} \\
\hline & & Agronegócio & 02 & & \\
\hline & & Idosos & 02 & & \\
\hline & \multirow{2}{*}{ Agronegócio } & Agricultura Familiar & 02 & & \\
\hline & & Pecuária & 02 & & \\
\hline & Financiamento Público & Agricultura Familiar & 02 & & \\
\hline & Setor Madeireiro & Legislação & 02 & & \\
\hline & \multirow{2}{*}{ Plantas Medicinais } & Agronegócio & 02 & & \\
\hline & & Desenvolvimento & 02 & & \\
\hline \multirow{8}{*}{$\begin{array}{l}\text { Meio } \\
\text { Ambiente }\end{array}$} & Inundações urbanas & Riscos Ambientais & 02 & \multirow{8}{*}{8} & \multirow{8}{*}{9,09} \\
\hline & Legislação & Meio Ambiente & 02 & & \\
\hline & \multirow{4}{*}{ Meio Ambiente } & Legislação & 02 & & \\
\hline & & Desenvolvimento & 02 & & \\
\hline & & Políticas Públicas & 02 & & \\
\hline & & Água & 02 & & \\
\hline & Resíduos Sólidos & Inovação Tecnológica & 02 & & \\
\hline & Riscos Ambientais & Gasoduto & 02 & & \\
\hline \multirow{6}{*}{$\begin{array}{l}\text { Indústria ou } \\
\text { Comércio }\end{array}$} & \multirow{4}{*}{ Setor Madeireiro } & & 02 & \multirow{6}{*}{6} & \multirow{6}{*}{6,82} \\
\hline & & Desenvolvimento & 02 & & \\
\hline & & & 02 & & \\
\hline & & Legislação & 02 & & \\
\hline & Setor Moveleiro & \multirow{2}{*}{ Desenvolvimento } & 02 & & \\
\hline & Associação Comercial & & 02 & & \\
\hline \multirow{5}{*}{$\begin{array}{l}\text { Planejamento } \\
\text { e Gestão }\end{array}$} & Gestão Privada & \multirow{5}{*}{ Desenvolvimento } & 01 & \multirow{5}{*}{5} & \multirow{5}{*}{5,68} \\
\hline & Incubadoras & & 01 & & \\
\hline & $\begin{array}{l}\text { Índice de Desempenho } \\
\text { Municipal }\end{array}$ & & 02 & & \\
\hline & Parceria Público Privada & & 02 & & \\
\hline & Plano Diretor & & 02 & & \\
\hline \multirow{4}{*}{$\begin{array}{l}\text { Assistência e } \\
\text { Inclusão } \\
\text { Social }\end{array}$} & Financiamento Público & Família & 01 & & \\
\hline & Inclusão Social & Trabalho e Emprego & 01 & & \\
\hline & Pobreza & Desenvolvimento & 01 & 4 & 4,55 \\
\hline & Assistência Social & Vulnerabilidades & 02 & & \\
\hline & Extensão Universitária & Desenvolvimento & 01 & & \\
\hline Desenvolvime & Cooperativa & Agricultura Familiar & 02 & & \\
\hline nto & Instituição de Ensino & Desenvolvimento & 02 & 4 & 4,55 \\
\hline & Superior & Território da Cidadania & 02 & & \\
\hline & Crianças ou Adolescentes & & 01 & & \\
\hline & História do Contestado & Contulos & 01 & 4 & 455 \\
\hline Justıça & Ocupação de Terras & Assentamentos Rurais & 02 & 4 & 4,55 \\
\hline & Segurança & Legislação & 02 & & \\
\hline & Desigualdades Raciais & Mulheres & 01 & & \\
\hline & & Agricultura Familiar & 01 & 1 & \\
\hline Mulheres & Mulher & Dissoluções Familiares & 01 & 4 & 4,55 \\
\hline & Violência & Mulheres & 01 & & \\
\hline & & Desenvolvimento & 01 & & \\
\hline Descentraliza & Descentralização & Educação & 01 & 3 & 3,41 \\
\hline & & Legislação & 02 & & \\
\hline
\end{tabular}

DRd - Desenvolvimento Regional em debate (ISSNe 2237-9029)

v. 6, n. 2, ed. esp., p. 5-25, jul. 2016. 
(Conclusão...)

\begin{tabular}{|c|c|c|c|c|c|}
\hline \multirow{3}{*}{ Esporte } & \multirow{3}{*}{ Esporte } & \multirow{2}{*}{ Crianças ou Adolescentes } & 01 & \multirow{3}{*}{3} & \multirow{3}{*}{3,41} \\
\hline & & & 01 & & \\
\hline & & Desenvolvimento & 01 & & \\
\hline \multirow{3}{*}{$\begin{array}{l}\text { Território da } \\
\text { Cidadania }\end{array}$} & \multirow{3}{*}{ Território da Cidadania } & \multirow{3}{*}{ Desenvolvimento } & 02 & \multirow{3}{*}{3} & \multirow{3}{*}{3,41} \\
\hline & & & 02 & & \\
\hline & & & 02 & & \\
\hline \multirow{2}{*}{$\begin{array}{l}\text { Crianças e } \\
\text { Adolescentes }\end{array}$} & Legislação & Trabalho Infantil & 01 & \multirow{2}{*}{2} & \multirow{2}{*}{2,27} \\
\hline & Mortalidade Infantil & Vulnerabilidades & 02 & & \\
\hline \multirow{2}{*}{$\begin{array}{l}\text { Indicação } \\
\text { Geográfica }\end{array}$} & \multirow{2}{*}{ Indicação Geográfica } & \multirow{2}{*}{ Desenvolvimento } & 02 & \multirow{2}{*}{2} & \multirow{2}{*}{2,27} \\
\hline & & & 02 & & \\
\hline \multirow{2}{*}{$\begin{array}{l}\text { Micro e } \\
\text { Pequena } \\
\text { Empresa }\end{array}$} & Microcrédito & Micro e Pequena Empresa & 01 & \multirow[b]{2}{*}{2} & \multirow[b]{2}{*}{2,27} \\
\hline & Micro e Pequena Empresa & Desenvolvimento & 02 & & \\
\hline \multirow{2}{*}{$\begin{array}{l}\text { Planejamento } \\
\text { Urbano }\end{array}$} & \multirow{2}{*}{ Planejamento Urbano } & Educação & 01 & \multirow{2}{*}{2} & \multirow{2}{*}{2,27} \\
\hline & & Desenvolvimento & 02 & & \\
\hline \multirow{2}{*}{$\begin{array}{l}\text { Trabalho e } \\
\text { Emprego }\end{array}$} & Segurança & Setor Madeireiro & 01 & \multirow{2}{*}{2} & \multirow{2}{*}{2,27} \\
\hline & Educação & Trabalho e Emprego & 01 & & \\
\hline \multirow{2}{*}{ Turismo } & \multirow{2}{*}{ Turismo } & \multirow{2}{*}{ Desenvolvimento } & 01 & \multirow{2}{*}{2} & \multirow{2}{*}{2,27} \\
\hline & & & 02 & & \\
\hline Comunicação & Comunicação & Desenvolvimento & 02 & 1 & 1,14 \\
\hline \multicolumn{3}{|l|}{ TOTAL } & \multicolumn{2}{|c|}{88} & 100,00 \\
\hline
\end{tabular}

Fonte: Secretaria PMDR (2016)

Com os estudos desenvolvidos, é possível afirmar que o PMDR contribui para o desenvolvimento em dimensões e escalas diferenciadas.

\section{AS CONTRIBUIÇÕES DO PMDR AO DESENVOLVIMENTO}

Das dissertações defendidas durante esses 10 anos do PMDR, destacam-se algumas para confirmar que o desenvolvimento é multiprofissional e interdisciplinar.

O estudo Desenvolvimento do Setor Madeireiro no município de Canoinhas (SC), período 1940 a 2007 resgatou a história socioeconômica do município, as empresas que formaram a estrutura fabril da madeira durante 67 anos, do auge ao declínio, bem como as sobreviventes das transformações de mundo produtivo-econômico. Concluiu que a falta de dados relacionados ao setor madeireiro tais como: produção, rotatividade de funcionários, custos e lucratividade, projetos inovadores, cooperação entre empresários que fazem parte do Sindicato das Indústrias de Serrarias, Carpintarias, Tanoarias, Madeiras Compensadas, Aglomerados e Chapas de Fibras de Madeira de Canoinhas (SINDIMADEIRA), foram os elementos estimuladores do estudo, que constatou a falta de infraestrutura suficiente desse sindicato para coordenar a cooperação entre empresas e empresários. Se essa contribuição não acontecer, projetos inovadores dificilmente surgirão como respostas de sustentabilidade ao setor madeireiro local-regional. Um dos encaminhamentos propostos pelo estudo foi a articulação entre os atores envolvidos para estabelecer uma melhor cooperação e desempenho, direcionados ao horizonte holístico e global do setor madeireiro, não apenas em nível local e por interesses de alguns integrantes do sistema. 
Abordando o setor florestal, a pesquisa Possibilidades e desafios do manejo de fragmentos de floresta ombrófila mista como alternativa de desenvolvimento: um estudo com base na realidade socioeconômica ambiental em Canoinhas (SC), evidencia oportunidades que podem ser destacadas como fatores para a conservação e uso racional desses fragmentos existentes no município citado, além de se transformarem em alternativas de trabalho e renda. Dentre os resultados pelo manejo florestal de PFMN, é a viabilização de serviços ambientais e o enriquecimento de florestas, tais como o adensamento com erva mate nativa para estruturação de sistemas agroflorestais sob a forma de caívas. Apesar dos desafios, um conjunto de oportunidades para o uso dos remanescentes nativos pode ser planejado no médio e longo prazos, de maneira a permitir que seus vários potenciais de uso se sustentem ao longo dos tempos.

A pesquisa Plano Diretor como Indicador de Políticas Públicas para o Desenvolvimento do Município de São Bento do Sul, reconstruiu o processo de elaboração e implementação do Plano Diretor de São Bento do Sul, SC, de 1974 e 2006. A partir das propostas e práticas desenvolvidas nessa prefeitura para elaboração do Plano Diretor de Desenvolvimento Integrado, conclui-se que as ações propostas pelos Planos Diretores, relacionaram-se à infraestrutura geral para a cidade, em relação ao sistema viário, aos locais para instalação de indústrias e comércio. Essas propostas eram as que o capital industrial necessitava para sua acumulação e expansão, o que motivou sua defesa e aplicação pelos setores dominantes locais, garantindo mesmo com a descontinuidade administrativa a consolidação de uma estrutura de planejamento na prefeitura.

Ao pesquisar o Turismo religioso e o desenvolvimento local de Itaiópolis-SC, o estudo indica que o potencial de desenvolvimento econômico é consolidado pela riqueza cultural. Para intensificar o desenvolvimento local, o estudo indica investimentos na atividade turística-religiosa como um nicho de mercado que pode ser mais explorado por empresas, prefeitura e população local, uma vez que se verifica que a cultura local tem potencialidade a ser explorada para o desenvolvimento do turismo religioso em Itaiópolis.

Outra pesquisa sobre a Arquitetura Art Déco em Canoinhas (SC):diagnóstico e potencialidades no contexto do desenvolvimento urbano-regional, apresenta rico acervo de edificações em Art Déco, em especial na área urbana de Canoinhas. Este acervo não está a salvo de demolição ou sequer de preservação, não existe processo de tombamento para esse estilo arquitetônico. A indicação do estudo que vai repercutir no desenvolvimento local, seria ao poder público uma ação de preservação deste estilo arquitetônico, como valor estético, no sentido de valorizar ícones da cidade. A comparação com outras cidades que se tornaram patrimônio cultural sustenta os argumentos para que esses recursos possam potencializar o desenvolvimento turístico da cidade, a economia da cultura como propulsora do desenvolvimento.

A dissertação sobre as Dimensões da territorialidade da saúde: estudo do movimento da humanização do parto na região da AMPLANORTE constata que o movimento da humanização na saúde pública, aplicada na região da AMPLANORTE é muito incipiente. As estruturas de instituições públicas necessitam adaptação ao ambiente favorável para a humanização. Apesar do incentivo efetivo dos governos pelas políticas públicas, tanto em capacitação de profissionais como em recursos financeiros para melhorar a qualidade de assistência oferecida a gestantes e recém-nascidos, na prática a sua efetivação não é ampla e completa. $\mathrm{O}$ número de profissionais é insuficiente para a demanda e para a assistência que se 
pretende oferecer, além de ser mal organizado, pois a assistência à gestante em trabalho de parto sem complicações poderia ser realizada por enfermeiras obstetrizes. Como também os partos com distócias e gestações de risco podem ser realizados pelo profissional médico. $\mathrm{O}$ número de cesarianas é alto em comparação aos considerados ideais pelo Ministério da Saúde, porém, são menores do que em outras a regiões do Brasil.

$\mathrm{Na}$ pesquisa Pobreza no Planalto Norte Catarinense: representações sociais e implicações no desenvolvimento regional identificam-se pelo discurso dos sujeitos participantes, a falta de oportunidade de trabalho digno e a baixa escolaridade como fatores influenciadores da pobreza em que vivem. Pode-se concluir que os elementos identificados reforçam a visão de que o desenvolvimento da região também está relacionado à sensação de liberdade de escolhas e do envolvimento social de seus sujeitos, permitindo que estes possam fazer e se sentir ativos no processo de crescimento pessoal e crescimento de seu território. A ausência de entendimento sobre o seu crescimento pessoal impede a leitura de crescimento de território.

Ao estudar as Políticas públicas e desenvolvimento regional: a inclusão da pessoa com deficiência no mercado de trabalho na região da $26^{\text {a }}$ Secretaria de Desenvolvimento Regional, os resultados possibilitam identificar a necessidade de melhor preparo de todos os órgãos públicos e privados, as famílias e as pessoas com deficiência, no que tange a inclusão destas ao mercado de trabalho. Essa inclusão é uma tarefa interativa entre os segmentos sociais com probabilidade de sucesso, se todos os segmentos se comprometerem com ações específicas. Ainda há a importância de um conhecimento específico e de preparo educacional com ações pedagógicas mais condizentes com a perspectiva de inclusão e não de segregação, pelas pessoas com deficiência.

Ao estudar A política de descentralização administrativa e o desenvolvimento regional em Santa Catarina, os resultados demonstram que embora o principal objetivo da descentralização seja diminuir as desigualdades regionais priorizando investimentos nas regiões menos desenvolvidas do Estado, o que ocorre na verdade é a concentração de investimentos nas regiões mais desenvolvidas. Esse resultado corrobora, em parte, com as hipóteses apresentadas de que a atuação das SDR está relacionada ao padrão de desenvolvimento regional e depende tanto da capacidade de aprendizado regional, quanto da capacidade de articulação política.

A pesquisa As políticas públicas na transição da produção de fumo para leite em pequenas propriedades rurais do município de Irineópolis (SC) sob a ótica da "tríade" social, econômica e ambiental, confirma a importância e contribuição das políticas públicas como ferramenta decisiva ao desenvolvimento das pequenas propriedades da comunidade e do município em questão, ou seja, por extensão ao desenvolvimento regional.

A dissertação que aborda a Agricultura familiar: um estudo a respeito do trabalho da pessoa idosa no cultivo do tabaco na região de Canoinhas (SC), conclui que a cultura do tabaco é economicamente sustentável na região. É a principal fonte de renda para as famílias produtoras, utiliza mão de obra praticamente toda familiar e as pessoas idosas estão inseridos no processo produtivo dessa cultura em todas as fases do cultivo e em grande número, ou seja, o idoso nesse cenário é parte integrante ativo na fumicultura local-regional. 
O estudo da dissertação Um olhar sobre a implantação do Programa Ensino Médio Inovador (PROEMI) em duas escolas públicas da 26 Gerência de Educação: uma análise indica resultados de que o Ensino Médio vem se desenvolvendo lentamente, mas aguardando melhorias físicas, financeiras e pedagógicas. Observando os dados apresentados, para 19\% dos alunos se têm necessidade do estabelecimento de políticas consistentes para a garantia de qualidade do ensino inovador, inseridos no redesenho imediato dos currículos, consoantes com a consolidação desta etapa da educação formal. Diante desses resultados, apesar da oferta de acesso ao ensino médio, ainda existe a preocupação com a permanência e a qualidade do ensino realizado. Cabe destacar que apenas as intenções de melhorias nos currículos não garante um ensino de qualidade, mas se conciliados, os resultados podem ser significativos.

Abordando o tema Impacto socioeconômico da universidade numa visão da economia do conhecimento: estudo de caso do campus Canoinhas da Universidade do Contestado (UnC), o estudo permite concluir que em cada real gasto pela universidade significa um efeito quase que triplicado sobre o produto e renda regionais do município. $\mathrm{O}$ impacto econômico total no município de Canoinhas foi cerca de 252,8 milhões de Reais, e que a UnC contribuiu com correspondente a $6,47 \%$ do PIB desse município. A UnC promove desenvolvimento econômico local-regional.

A pesquisa sobre o Instituto Federal de Educação, Ciência e Tecnologia de Santa Catarina - IFSC - campus Canoinhas: uma análise da implantação e função social no desenvolvimento do território da cidadania do Planalto Norte Catarinense, demonstra que a sociedade como um todo deposita confiança e expectativa no trabalho desenvolvido pela Instituição e pelo Campus Canoinhas. Os dados coletados comprovam que a implantação do IFSC contribui para o desenvolvimento do Território da Cidadania do Planalto Norte Catarinense. É necessário que se registre a parcialidade que esse fomento representa, pois a receptividade às ações do IFSC no Território da Cidadania do Planalto Norte Catarinense, é melhor nas cidades mais próximas de Canoinhas (Major Vieira, Três Barras e Bela Vista). Quanto maior é a distância entre as cidades no Território em relação ao município sede do Campus, menor ou nulo é o nível de abrangência das atividades da instituição.

Ao abordar $\mathrm{O}$ cenário das violências contra as mulheres em municípios da região do Planalto Norte Catarinense, observa-se que os espaços em que a violência está mais presente é o privado, ou seja, no domicílio, ou o dito familiar. A violência doméstica é evidente no território estudado e a forma de violência predominante entre as classificações referendadas pela Lei Maria da Penha é a moral seguida pela psicológica tendo como agressor, homens que em algum momento efetivaram laços familiares. Fica evidente, após análise dos dados, que as políticas públicas para o enfrentamento da violência contra as mulheres buscam a erradicação desta, evoluíram orientando articulação entre os espaços de atenção às mulheres vítimas de violência. Porém, não estão efetivamente sendo implantadas pelas mais variadas questões: desinteresse, desconhecimento e vontade política para efetivá-las.

Outro tema estudado refere-se à Política pública de segurança: uma análise da lei municipal de restrição ao consumo de bebidas alcoólicas em munícipios da $26^{\text {a }}$ SDR, o qual conclui que a relação existente entre desenvolvimento e segurança, decorre da necessidade de se manter um clima de harmonia e paz social, para que as atividades econômicas se desenvolvam sem risco para as pessoas. A violência e os índices de criminalidade podem ser determinantes para a escolha de um local de implantação de um projeto ou de um empreendimento que vise promover desenvolvimento. Com os resultados obtidos pela revisão 
da literatura e com a pesquisa de campo, foi possível constatar que a população dos municípios pesquisados se posiciona a favor da implementação de políticas públicas por meio de leis para o reestabelecimento da Ordem Pública.

A dissertação que apresenta estudos sobre A indicação geográfica de produtos: um estudo sobre a contribuição econômica no desenvolvimento territorial, sistematiza conhecimentos obtidos pela revisão da literatura e nas pesquisas de campo. Nela foi possível identificar a importância da Indicação Geográfica como vetor do desenvolvimento de territórios e regiões, salientando que isso não ocorre de forma autônoma, mas sim com a contribuição da sociedade civil e dos setores da economia que fazem parte do objeto da IG.

As dissertações defendidas no PMDR podem ser acessadas pelo site da UnC: www.unc.br/mestrado.

Com esses breves indicativos do muito que foi pesquisado, estudado, analisado, avaliado, ao longo de 10 anos, pode-se concluir que os âmbitos do desenvolvimento, localregional-nacional e internacional se entrelaçam, amalgamam-se, complementam-se, confrontam-se, contradizem-se.

Não é diferente no Planalto Norte Catarinense. Neste território, apresentam-se inúmeras questões e situações que podem se tornar objeto de pesquisa no PMDR e que podem contribuir para a ampliação da compreensão dos pressupostos antropológicos, econômicos, políticos, culturais, sociais que compõem e dinamizam o Planalto Norte Catarinense, o estado de Santa Catarina, o Brasil, materializando-se em consistentes ações de desenvolvimento.

\section{A INSERÇÃO E O ENVOLVIMENTO SOCIAL DO PMDR}

Para além da formação intelectual e científica dos Mestres em Desenvolvimento Regional, o contributo que o PMDR advém de sua inserção social por meio da sua presença e participação nos ambientes da sociedade local-regional em particular o que vem acontecendo no território do Contestado. O PMDR se faz presente em diversos espaços e conjuga, com diversos atores os processos e reflexões do desenvolvimento.

Entre as estratégias e os recursos utilizados, O PMDR tem o compromisso e vem promovendo profícuos debates, socializando os resultados de suas pesquisas e apresentando em suas publicações, avanços, resistências, retrocessos, desafios. Confia-se que como nunca a inserção social do PMDR vem oferecendo estrategicamente aprofundamentos teóricos, conceituais e práticos em torno de objetos e questões do desenvolvimento regional.

Ao longo dos seus 10 anos, o PMDR também promoveu eventos que abordaram temas como: estado e gestão pública, descentralização administrativa catarinense, inovações socioeconômicas e políticas, território, economia, gestão territorial, governança, estado, políticas públicas, centenário do contestado, meio ambiente e desenvolvimento regional, microcrédito, agronegócio, gestão pública municipal, empreendedorismo e território da cidadania, meio ambiente.

Esses eventos, com ampla participação da sociedade em geral, aproximam o ambiente acadêmico com os atores sociais quando as lideranças políticas, empresários, estudantes,

DRd - Desenvolvimento Regional em debate (ISSNe 2237-9029) 
professores, gestores de organizações não governamentais interagem sobre os desafios e impasses do desenvolvimento regional.

A comunicação, elemento central da presença e envolvimento do PMDR no ambiente social, é amplamente utilizada. O PMDR conduz a publicação de dois periódicos online, a DRd-Desenvolvimento Regional em debate e a Revista Profanações. Trata-se de uma estratégia das mais relevantes que certifica cientificidade aos conhecimentos, por meio dos seus compartilhamentos entre estudiosos, pesquisadores e cientistas. Trata-se de periódicos eletrônicos, de acesso público, disponíveis no site www.unc.br/biblioteca.

Além dos periódicos, a publicação de mais de 25 livros impressos ou online, (www.unc.br) é outro recurso estratégico de inserção social. $O$ hábito milenar do conhecimento escrito atrai a sociedade local-regional para os interesses do desenvolvimento, quando essas publicações são socializadas. Todas essas publicações foram financiadas por agentes de pesquisa e financeiros, o que favorece a distribuição gratuita e acessível à comunidade em geral.

Pelos jornais locais e regionais, os artigos e publicações com reflexões, reacendem a curiosidade, a dúvida, a afirmação. Mexe com o comodismo, desacomoda e sensibiliza. Este resultado rendeu quatro coletâneas Crônicas do Desenvolvimento, disponibilizadas à sociedade. Em 2016, prepara-se um quinto volume.

Ainda, a rádio educativa da Universidade do Contestado - UnC-FM $(100,5)$, é um recurso de longo alcance, no qual a comunicação se torna aliada das discussões acerca da realidade social, desafios e processos necessários ao desenvolvimento. $\mathrm{O}$ retorno desse alcance vem por meio das manifestações do impacto que os temas tratados ocasiona sobre os sujeitos.

Complementando o compromisso da inserção social, a atuação política dos docentes e discentes reveste-se de presença ativa no controle social de políticas públicas, no Conselho Municipal dos Direitos da Criança e do Adolescente; Conselho Municipal de Educação; Conselho Municipal de Saúde. Conselho Municipal de Assistência Social.

Não de menor presença, o PMDR por meio de seus docentes, constitui o capital social de instâncias colegiadas em permanente representação da Unc no Conselho Municipal de Desenvolvimento Sustentável (CMDS) do Município de Concórdia-SC; Conselho Municipal de Desenvolvimento Agropecuário (CONDEAGRO) do Município de Concórdia (SC); Conselho Fiscal da Organização da Sociedade Civil de Interesse Público (OSCIP) 'Queimados Vivo' - Rio dos Queimados do Município de Concórdia-SC; Conselho Diretivo Território da Cidadania do Planalto Norte e Território da Cidadania do Meio Oeste Catarinense; na Associação Catarinense das Universidades Fundacionais (ACAFE); Câmara Setorial de Certificação de Qualidade dos Produtos Agropecuários de Santa Catarina, Assessoramento técnico à Secretaria de Estado da Agricultura e da Pesca, Diretoria de Qualidade e Defesa Agropecuária; Comissão Técnica do Projeto de Articulação da Indicação Geográfica da erva mate no Planalto Norte Catarinense.

No que tange as redes nacionais e internacionais de pesquisas e estudos, o PMDR se faz presente no Observatório das Metrópoles, Observatório do Desenvolvimento Regional, na Rede ANIPES de pesquisa do IPEA, na Rede Iberoamericana de Estudos sobre Desenvolvimento Territorial e Governança (REDETEG), envolvendo pesquisadores do 
Brasil, Argentina, Portugal, Espanha e Polônia; Tutoria do Acordo Institucional da UnC e Universidad Castilla-La Mancha da Espanha.

Dessa participação e representação, o contributo do PMDR respalda a elaboração do Plano Municipal dos Direitos da Criança e do Adolescente; Plano Decenal de Medidas Sócio educativas de Canoinhas; Plano de Ação e Orçamento do Conselho Municipal de Direitos da Criança e do Adolescente de Canoinhas; Plano Municipal de Educação de Canoinhas (20152024).

Não apenas compor e nem representar a UnC e o PMDR, mas produzir fundamentos, cenários, dilemas e prospecção, esta tem sido a presença ativa do PMDR nas relações interinstitucionais que visam o desenvolvimento de estudos, pesquisas e produção de conhecimentos. Nesse entrelace, as pesquisas interinstitucionais no formato de redes, o PMDR fez e faz parte de pesquisas concluídas e em andamento nestes 10 anos de existências. Estas ações compartilhadas representam oportunidades de inserção social, tanto no âmbito regional, como nacional e internacional. Os docentes e pesquisadores então envolvidos com a UNESP Jaboticabal, área de imunodiagnóstico de parasitoses; no GRUPO PESQUISA UFSC: Cadastro técnico multifinalitário; Grupo de estudos sobre a capacidade de as organizações absorverem conhecimento de seu ambiente externo, formado por pesquisadores da UnC, da Unoesc, da Univali, da PUC/MG, da Unijuí, da Unisul, e da UDESC; no Grupo PALEOANTAR, com pesquisas paleontológicas na Antártida.

Os decentes estão envolvidos com ações e intervenções na UFRJ, coordenação do Museu Nacional; na Universidade Federal Rural de Pernambuco (UFRPE); na Universidade Federal de Pernambuco (UFPE); na Universidade Federal de Viçosa (UFV); na Universidade Federal do Espírito Santo (UFES); Universidade Federal de Uberlândia (UFU); no Instituto Antártico Argentino, Museo de La Plata e University of Alberta (Edmonton, Canada).

Entre as pesquisas relevantes desenvolvidas em grupos multiprofissionais e interinstitucionais, envolvendo docentes e discentes do PMDR, cita-se a pesquisa financiada pelo EDITAL N0 07/ 2008 CAPES/MINC, PROGRAMA PRÓ-CULTURA, integrando a UNISUL, UNIVILLE e UnC; como também a cooperação com o Observatório das Metrópoles e com o Instituto de Pesquisa Econômica Aplicada (IPEA), das quais renderam pesquisas, eventos e publicações.

A formação de atores sociais é outra atividade que mantém o PMDR em interação com a sociedade, quando conselheiros e gestores contam com a contribuição dos docentes para a melhoria das competências políticas desses atores. Ainda no âmbito da formação política, o PMDR se fez presente nas conferências municipais no território do Contestado, desde as edições de 2007 a 2015, proferindo as palestras principais para o controle social das políticas públicas de saúde, pessoa com deficiência, saúde ambiental, mulheres, idosos, assistência social, crianças e adolescentes.

$\mathrm{Na}$ linha de frente da promoção do desenvolvimento regional, a interação com a Associação dos Municípios do Planalto Norte (AMPLANORTE) na qual prefeitos, secretários municipais e representantes de diversas instituições, formam um coletivo que nos últimos quatro anos vem concebendo um programa voltado ao Planalto Norte Catarinense.

Mas o reconhecimento vem. Prova disso, são as premiações dos Mestres em Desenvolvimento Regional. Jorge Amaro Bastos Alves, classificou-se em $1^{\mathrm{o}}$ lugar no III

DRd - Desenvolvimento Regional em debate (ISSNe 2237-9029) 
Prêmio BRDE de Desenvolvimento-SC, concedido pelo Banco Regional de Desenvolvimento do Extremo Sul (BRDE) e Conselho Regional de Economia de SC. Também foi contemplado pelo $1^{\circ}$ lugar no Prêmio Luiz Henrique da Silveira, concedido pelo Programa de Mestrado em Desenvolvimento Regional - UnC.

No ano de 2013, o Mestre Edson Cogo recebe menção honrosa do Ministério da Integração Nacional, no Prêmio Celso Furtado de Desenvolvimento Regional, na Edição 2012: homenagem à Rômulo de Almeida. Ainda em 2013, a Mestre em Desenvolvimento Regional, Bruna Rayet Ayub, recebe o Prêmio SCHUH como melhor Dissertação de Mestrado em Economia Rural pela Sociedade Brasileira de Economia, Administração e Sociologia Rural, na $51^{\circ}$ SOBER.

As ações acima relatadas demonstram o compromisso do PMDR com a inserção social como forma de contribuir com o avanço das ideias, das reflexões e, de práticas virtuosas em âmbito público, privado e social em relação ao desenvolvimento regional.

\section{OS IMPASSES E OS ENFRENTAMENTOS DO PMDR PARA O DESENVOLVIMENTO DO PNC}

Um dos impasses iniciais do PMDR diz respeito ao recente processo da interiorização do Stricto sensu no Brasil. De tradição litorânea e concentrada em centros urbanos considerados referências nacionais, a oferta e localização de mestrados e doutorados em regiões no interior do Brasil, passaram a enfrentar a aceitação, reconhecimento e porque não dizer, com o preconceito da elitização desse nível de formação.

Mas estimulados pela política pública educacional e da promoção da ciência, tecnologia e inovação, em 10 anos esse cenário vem sendo modificado. O PMDR, nesse quesito, é precursor, sendo o primeiro a ser ofertado num raio de 200 quilômetros, no interior do estado de Santa Catarina.

Entre os enfrentamentos, há as condições objetivas que retêm o interesse e o desejo da formação pelos diversos atores. A necessidade de custeio das mensalidades interfere na opção e na conclusão do curso por mestrandos submetidos às alterações sociais e mercantis. Por isso, a evasão dos mestrandos foi um dos impasses para a sua sustentabilidade e a reação advém das bolsas de estudos e pesquisas que respaldaram a permanência e a finalização do mestrado.

No ambiente do PNC, o desenvolvimento e seus desafios não cessam. Os estudos e as pesquisas revelam que as superações de cenários e dilemas, em cada fase da organização social desse território, tornam-se evidentes ao mesmo tempo em que paradoxais.

No primeiro olhar, a riqueza local-regional se expressa nas cores das árvores, nas abundantes águas, no solo vermelho prometendo vida. $\mathrm{O}$ ar é límpido. Há proximidade entre os lugares, 70 quilômetros de estrada ligam quatro municípios.

Por outro, economia e a sociedade são desafiadas cotidianamente para manterem certo grau de bem estar.

DRd - Desenvolvimento Regional em debate (ISSNe 2237-9029) 
Entre as questões invisíveis, dada a marca material no imaginário da sociedade como valor único para o desenvolvimento, os impasses, que contradizem a rica fisionomia desse território, podem ser assim elencados:

-desenvolvimento é associado ao crescimento econômico;

-a população não se reconhece como copartícipe do desenvolvimento;

-elitização do poder, reproduzindo a relação poder político com poder econômico, distanciam a presença ativa na gestão pública e gestão social;

- concepção equivocada sobre a composição e atribuições das políticas públicas como estratégias para o desenvolvimento, o que de fato deve produzir bem estar;

-desconhecimento da relação inerente entre direitos, políticas públicas, gestão, atribuições dos atores sociais nesse amálgama;

-falta da intersetorialidade na execução das políticas públicas;

-o controle social não é reconhecido como espaço para o exercício da democracia;

-descontinuidade das ações, programas e intervenções nas alterações das gestões;

-resistências culturais quanto a cooperação;

-imaginário reproduz sentimento de subalternização como marca identitária;

-saber restrito ao âmbito institucional e não popular;

Estes são breves indicativos extraídos dos estudos, pesquisas e análises sobre o PNC, inseridos na agenda dos desafios da UnC e do PMDR, que na interlocução com os atores sociais desse território, tornam-se as perspectivas ao desenvolvimento nas suas múltiplas dimensões.

\section{OS DESAFIOS E PERSPECTIVAS AO PMDR PARA O PNC}

Nos 45 anos de UnC e nos 10 anos do PMDR, atores relevantes do desenvolvimento afirmam sua posição e se investem de compromisso para a continuidade de seu contributo visando mudanças, superações e as transformações necessárias ao seu território de abrangência.

De trajetória densa, complexa, paradoxal, o espaço - PNC - e os atores sociais entre eles a UnC e o PMDR, devem solidarizar-se para que impasses se tornem desafios e enfrentamentos se tornem perspectivas.

Tomadas uma a uma as questões visualizadas nos diagnósticos e reflexões dentro do PMDR e sobre o PNC, pela interlocução com a sociedade local-regional, para esse processo, o saber cotidianamente produzido deve ser resignificado. 
As questões resumem indicativos que devem tornar visível o que é e quem é o território do Planalto Norte Catarinense. Da convivência naturalizada, pobreza-riqueza, deve emergir um sentimento de indignação sobre a tradicional e marcante atribuição ao crescimento econômico, como único redentor da estagnação e apatia político-social, como também da inclusão social.

Para além de enaltecer a riqueza e beleza da fisionomia geográfica e ambiental, os atores do PNC devem situá-la como parte dos recursos e estratégias do bem estar e qualidade de vida. A paisagem corrobora a produção, a dinâmica social e política como perspectiva de desenvolvimento. Portanto, para além de se considerar recurso prioritário do crescimento econômico, essa riqueza deve ser inserida na superação dicotômica riqueza-pobreza, de forma extensiva, universalizada e universalizante.

No PNC todos devem ser beneficiados com essa riqueza, mas para que isso aconteça, um primeiro passo de mudança deverá estabelecer associações entre necessidades humanosociais, com crescimento social, com inclusão social, com empoderamento político.

Longe de ser uma sociedade participativa, a responsabilidade pelo desenvolvimento que historicamente fez distinção de classe, não pode mais permanecer atribuída a um ator apenas. O Estado e os governos, na sociedade democrática e de direito são constituídos de sujeitos ativos, presentes. Fato que desafia a UnC, formadora dos sujeitos (profissionais e políticos) a revisarem continuamente a histórica separabilidade homo faber do homo sapiens.

Portanto, o PMDR pode ser um ator mobilizador, apoiador, instigador, formador, subsidiador dos recursos teórico-filosóficos, técnicos-operativos, ético-políticos, ao lado, não à frente desse processo. Há a compreensão de que a população do $\mathrm{PNC}$, extensiva ao território do Contestado, precisa assumir mais a sua condição de copartícipe do desenvolvimento.

O PMDR, nos seus 10 anos, vem alertando sobre esses processos políticos (aqui considerado os déficits econômicos, sociais, ambientais, políticos e culturais) vigentes e vem instigando a revisão dos valores sociais para o exercício do poder cooperativo e solidário. Como perspectiva assumida na missão prioritária do PMDR, explícita na sua concepção, a análise diuturna da composição do poder de classes, remanescentes dos primórdios do processo produtivo urbanizado e industrial, perfil predominante do PNC, deve submeter-se a intensa e crítica revisão. Logo, eis o desafio do PMDR para os próximos 10 anos.

Ainda, neste viés, a deselitização do poder é uma das perspectivas do desenvolvimento local-regional quando a participação política da população passa a ser mais presença ativa na gestão pública e gestão social. Sem paixões unicistas, mas compreendendo que a interdisciplinaridade é parte inerente ao exercício das transformações, o PNC precisa revitalizar sua identidade, contextualizar-se não pela lógica global economicista. Precisa introduzir no imaginário, novos imaginários. Fisicamente, esse território conecta-se com o mundo, mas ideologicamente intimida-se em uma reclusão de estima baixa, reproduzindo os cenários contraditórios ao desenvolvimento. Neste, igualdade e justiça social, devem ser parâmetros de sensibilização, de mobilização, da processualidade sócio histórica necessária ao PNC.

Em tal paradoxo, o contraditório emerge entre o vivido sob norte do imaginário que reproduz sentimento de subalternização como marca identitária, com a pressão da revalorização da riqueza social, produtiva e intelectual, forçando de fora para dentro. Assim o 
PMDR tem um desafio de contornar a leitura de realidade socioeconômica, política, ética e ambiental, para que o desenvolvimento aconteça de dentro para fora.

Portanto, saberes multiprofissionais devem se somar às distintas demandas das classes, os quais precisam extrapolar os muros institucionais. O sentido de pertencimento deve passar por uma revisão ético-política para tornar todos os atores copartícipes da superação do autoflagelo e lamuriante discurso de território pobre, estagnado, sem saída a não ser pelo salvador mercado.

Nesse território, deve-se superar a concepção equivocada ainda reinante do sentido e significado da composição e atribuições das políticas públicas. Como estratégias para o desenvolvimento, a relação inerente entre direitos, políticas públicas, gestão, atribuições dos atores sociais nesse amálgama, deve ser contornado pela compreensão da responsabilidade política de cada sujeito com o bem estar.

As concepções do equivocado individualismo, evidentes nas intervenções, é outro desafio. Agregar ao bem estar o exercício político da intersetorialidade na execução das políticas públicas tornaria eficaz a sua intervenção. Além da posição política da gestão pública, a gestão social e da sociedade, precisa reconhecer as redes relacionais desse composto complexo recurso institucional, público, de direito e de deveres. Porém, não sem as resistências das micro hegemonias, construídas ao longo do percurso da composição das políticas públicas e das sociais, setorializando as necessidades humanas e sociais. Se esse foi um recurso estratégico de fortalecer o desenvolvimento econômico e consolidar um modelo político liberal-neoliberal, deu certo. Mas no contorno do caos, na revisão dos processos sociais, na sociedade brasileira, a reação veio por meio de certa maturidade política expressada na Constituição brasileira de 1988.

Com base no conhecimento da histórica negligência com o saber social, popular, universalizado, além de não se reconhecer as transformações societárias, a falta de incentivo e de interesse ainda não atingiu os sujeitos. Logo na sociedade local-regional, o controle social, de longe é reconhecido como espaço de direitos e de deveres, de permanente presença ativa para a definição da constante melhoria dos recursos necessários, por conseguinte do desenvolvimento. Muito menos o controle social é relacionado com o exercício da democracia.

Além do que já foi oportunizado pelo PMDR nesse processo, restam relevantes perspectivas que sistematicamente tomam parte da agenda dos seus compromissos políticos. Sem que se coloque na atribuição de ator mobilizador a presença ativa nas instituições públicas e não públicas, torna-se uma estratégia de contribuição ao enfrentamento desse desafio.

Se o amálgama das políticas públicas, das atribuições institucionais for reconhecido, bem como, ocorrer melhoria no status quo da inserção e presença dos sujeitos na vida ativa no território, almeja-se um salto qualitativo. Não se trata da passagem da quantidade para a quantidade. Esse desafio é sim um investimento em quantidade e qualidade. Não se promove o desenvolvimento com poucos atores. Esses irão fatalmente privilegiar seus interesses. É o que o mercado proporcionou até o momento. Não é estranho que o desenvolvimento contemple o equivocado significado de crescimento econômico. Permanecem desafios. Como enfrentá-los? 
Em outra via, corrobora o distanciamento entre sujeitos e os processos sociais, da sua sociedade, quando é evidente a descontinuidade das ações, programas e intervenções nas alterações das gestões. O sentido de permanência e perpetuação que indique transformações, deve ser proporcionado pelos saltos qualitativos visualizados tanto em estruturas sociais como nas quebras das resistências culturais que impedem aos atores atuarem cooperativamente.

Não resta dúvida de que nos últimos 150 anos, o PNC formata cenários distintos, que sustentam identidades, demandas e desafios. Na somatória das intervenções sociais, os atores, entre eles o PMDR inclui nas discussões nacionais e internacionais as peculiaridades desse território. Muito se fez, muito há de se fazer: superar os desafios e contribuir com as perspectivas e realizações do desenvolvimento desse e de outros territórios, é o compromisso da UnC e do PMDR.

\section{REFERÊNCIAS}

BRASIL. Conselho Nacional de Educação. Parecer CNE/CES 165/2006, aprovado em 08 de junho de 2006. Diário Oficial da União, n. 121, Seção 1, p 34, 27 jun. 2006.

Ministério da Educação. Portaria ${ }^{\circ}$ 524, de 29 de abril de 2008. Diário Oficial da União, n. 82, Seção 1, p. 52, 30 abr. 2008.

Portaria ${ }^{\circ} 679$ de 15 de março de 2006. Diário Oficial da União, n. 52, 16 mar. 2006, seção 1, p.09.

CANOINHAS. Lei municipal $\mathbf{n}^{\mathbf{0}} \mathbf{9 5 4}$, de 07 de dezembro de 1970, do município de Canoinhas/SC.

COORDENAÇÃO DE APERFEIÇOAMENTO DE PESSOAL DE NÍVEL SUPERIOR (CAPES). Ofício nº 177_13_2006/CTC/CAPES, 07 fev. 2006.

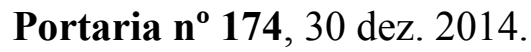

\section{FUNDAÇÃO UNIVERSIDADE DO CONTESTADO. Estatuto Social da Fundação Universidade do Contestado.}

PHILIPPI JUNIOR, Arlindo; SILVA NETO, Antônio J. Interdisciplinaridade em ciência, tecnologia e inovação. Barueri, SP: Manole, 2011.

SANTA CATARINA. Conselho Estadual de Educação. Decreto ${ }^{\circ} 1.531$, de 15 de julho de 2008. Diário Oficial de Santa Catarina, n. 18.402, p. 03, 15 jul. 2008.

Parecer CEDS $\mathbf{n}^{\circ}$ 42, aprovado em 22 de maio de 2006 - CEE/CES processo PCEE $138 / 068,2006$.

1997.

Parecer nº 246/97, do Conselho Estadual de Educação - CEE, de 03 dez.

Parecer no 42/97. Conselho Estadual de Educação - CEE. 21 out. 1997.

DRd - Desenvolvimento Regional em debate (ISSNe 2237-9029) 
. Resolução no 42/97/CEE/SC, de 03 dez. 1997. Recredenciamento: Decreto

1.748. Diário Oficial de Santa Catarina, 18 set. 2013.

. Resolução no 55 e Parecer CEE/SC n 141/2008, aprovado em 13 de maio

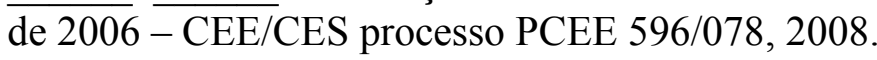

. Decreto ${ }^{\circ}$ 2106. Diário Oficial de Santa Catarina, n. 16.612, 02 mar. 2001.

Resolução no 001/2001/CEE/SC ou CNE/CES. 03 abr. 2001.

UNIVERSIDADE DO CONTESTADO. Aprovação da adequação do Programa de Mestrado em Desenvolvimento Regional, ao parecer da Comissão de Avaliação da CAPES, pela Resolução UnC-CONSEPE 018/2006, 22 mar. 2006.

. Portaria UnC 038-2006, 01 jul. 2006. jun. 2005.

Programa de Mestrado aprovado pela Resolução UnC-CONSEPE $\mathbf{0 2 0 / 2 0 0 5}, 01$

Projeto Pedagógico do Programa de Mestrado em Desenvolvimento Regional (2014), aprovado CONSUN, jan. 2014.

Relatório de renovação de credenciamento da Fundação Universidade do Contestado. nov. 2005.

Resolução UnC-CONSUN 019/2012. Regimento Interno do Programa de Mestrado em Desenvolvimento Regional, 2012. 